\title{
Alkali Activated Mortars with Intumescent Properties
}

\begin{abstract}
ADRIAN IONUT NICOARA, ALINA BADANOIU*, MAGDALENA BALANOIU, ALEXANDRA MATHIAS, GEORGETA VOICU
University Politehnica from Bucharest, Faculty of Applied Chemistry and Materials Science, 1-7 Gh. Polizu Str., 011061, Bucharest, Romania

The paper presents the properties of a new type of alkali activated borosilicate inorganic polymers (AABSIPS) resulted by the activation of waste glass powder and fly ash with alkaline solutions. The alkali activators used in this study were mixtures of borax decahydrate with $\mathrm{NaOH}$ and $\mathrm{KOH}$ solutions. For the preparation of $A A B S I P$ mortars two types of aggregates were used i.e. sand and a waste resulted during the mechanical processing of titanium alloy ingots. The thermal treatment of these pastes and mortars determines an intumescent process i.e. significant increase of volume; consequently, these materials could be used as low-cost fire stopper blocks for passive fire protection of buildings.
\end{abstract}

Keywords: Intumescent paste, mortar, fire protection, alkali activated materials, geopolymers

The geopolymer materials have been used in numerous and various applications fields, ranging from low technology products (bricks, ceramics, low $\mathrm{CO}_{2}$ cement and concretes), up to materials for niche applications (fire and heat resistant composites or radioactive or/and toxic waste encapsulation, etc).

Davidovits suggested that geopolymers could be used for high temperature and fire applications [1,2]. After curing for several hours, these materials display an excellent set of properties such as high strength and fire resistance; moreover, these materials do not emit toxic smoke during burning and resist to a wide variety of organic solvents [35].

All these special properties recommend geopolymeric materials as matrix in high-tech composites used in aerospace, marine and ground transportation especially for those applications which requires high temperature/ fire resistances $[3,4,6]$.

Williams et al. [7] reported the synthesis of a new class of materials (alkali activated borosilicate inorganic polymers - AABSIP) by the alkaline activation of silica fume with a sodium hydroxide solution with anhydrous borax addition; these authors proposed as potential application for this material the neutron shields. Nazari et al. [8] obtained boroaluminosilicate geopolymer materials, with high mechanical strengths, by the alkaline activation of fly ash (waste resulted in thermal power plant).

Our research group reported in $2015[9,10]$ the synthesis of alkali activated materials based on waste glass powder (WGP) with intumescent properties; this type of materials exhibit an important increase of volume when subjected to fire or thermal treatments at temperatures ranging from 600 to $800^{\circ} \mathrm{C}$. In a subsequent study [11] AABSIPs were obtained by the alkaline activation of WGP with an alkaline activator based on $\mathrm{NaOH}$ solution with anhydrous borax addition; for this type of materials the activation temperature of intumescent process decreases up to $500^{\circ} \mathrm{C}$. However, a drawback in the synthesis of this type of materials is determined by the rapid loss of workability of fresh mixtures most probably due to the formation of sodium borate hydrate. On the other side, the presence of this compound was beneficial from the point of view of intumescent properties.
In order to overcome this rapid increase of viscosity (loss of workability) we have studied also the influence of partial substitution of $\mathrm{NaOH}$ with $\mathrm{KOH}$, in the synthesis of this type of AABSIP materials [12]; the substitution of $\mathrm{NaOH}$ with $\mathrm{KOH}$ (up to $30 \%$ ) exert a positive influence not only on the workability of fresh paste (based on waste glass powder) butalso on the intumescent properties of resulted AABSIP materials.

This paper presents new information regarding the influence of various amounts of fly ash admixtures ( $5 \mathrm{wt} . \%$ and $10 \mathrm{wt} . \%$ ) on the main properties of intumescent pastes and mortars obtained by the waste glass pow der activation with $\mathrm{NaOH}+\mathrm{KOH}+$ borax decahydrate aqueous solutions.

The paper present also data regarding the influence of aggregate type (natural sand or a waste resulted in titanium industry) on the intumescent behavior of mortars based on this type of AABSIPs. To the best of our knowledge we report for the first time results related to the use of the above mentioned aggregates on the intumescent properties of this type of AABSIPS.

\section{Experimental part}

Materials and methods

Waste glass powder (WGP) was obtained by the fine grinding of soda-lime glass cullet. The Blaine specific surface area of WGP was $3000 \mathrm{~cm}^{2} / \mathrm{g}$.

Fly ash (class F) was obtained from a Romanian thermal power plant. The Blaine specific surface area of fly ash was $1806 \mathrm{~cm}^{2} / \mathrm{g}$. The mineralogical compounds assessed by X Ray Diffraction (XRD) in this fly ash were: silicon oxide (quartz) identified by PDF 83-2465, calcium aluminum silicate (anorthite) identified by PDF 76-0948 and magnesium silicate identified by PDF 03-0522.

The SEM images of waste glass powder and fly ash are presented in figure 1. It can be noticed the presence of angular glass grains with sharp edges and corners with various sizes (fig.la and b); as expected the main elements assessed by Energy Dispersive X-ray Analyze - EDAX (insert in fig. $\mathrm{lb}$ ) are $\mathrm{Si}$, $\mathrm{Na}$ and $\mathrm{Ca}$.

The fly ash grains have various sized and shapes (fig. 1c) ranging from irregular shapes to spherical cenospheres (fig. Id); the main elements assessed by EDAX (insert in fig. 1d) are: $\mathrm{Si}, \mathrm{Al}, \mathrm{K}, \mathrm{Ca}, \mathrm{Fe}, \mathrm{Mg}$. 


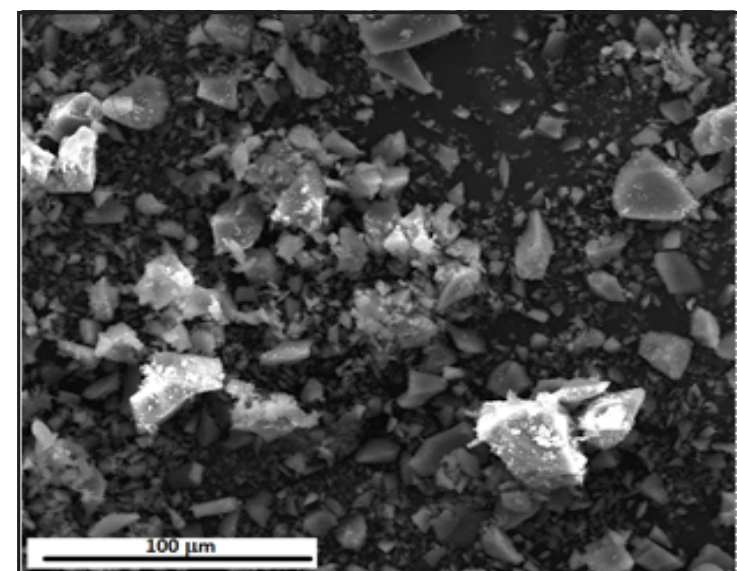

a

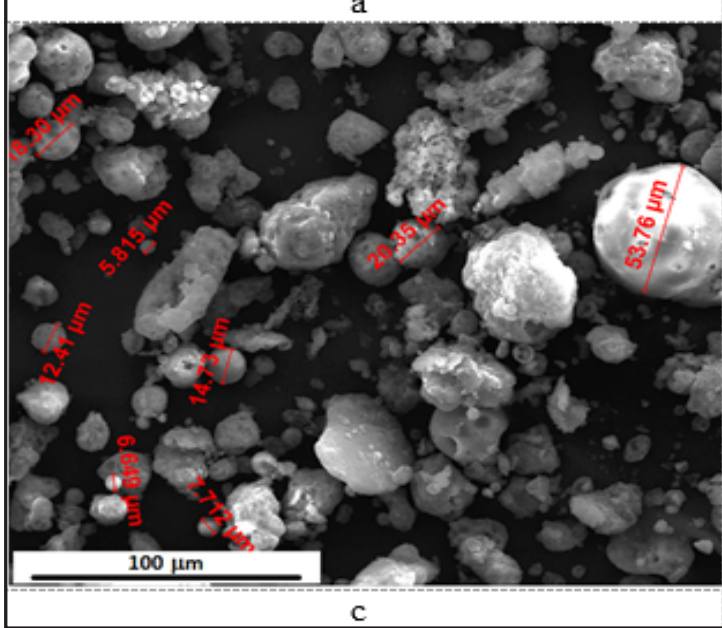

Borax decahydrate $\left(\mathrm{Na}_{2} \mathrm{~B}_{4} \mathrm{O}_{7}, 10 \mathrm{H}_{2} \mathrm{O}\right)$, sodium and potassium hydroxides, chemical reagent grade, were used for the preparation of alkali activator solution.

For the preparation of AABSIP mortars two types of aggregates were used:

- natural sand $(S)$ that fulfills the requirements of European/Romanian standard (SR EN 196-1, 2006);

- waste (W) resulted during the mechanical processing of titanium alloy ingots in the surface abrasion/polishing process with abrasive discs. This waste has a high amount

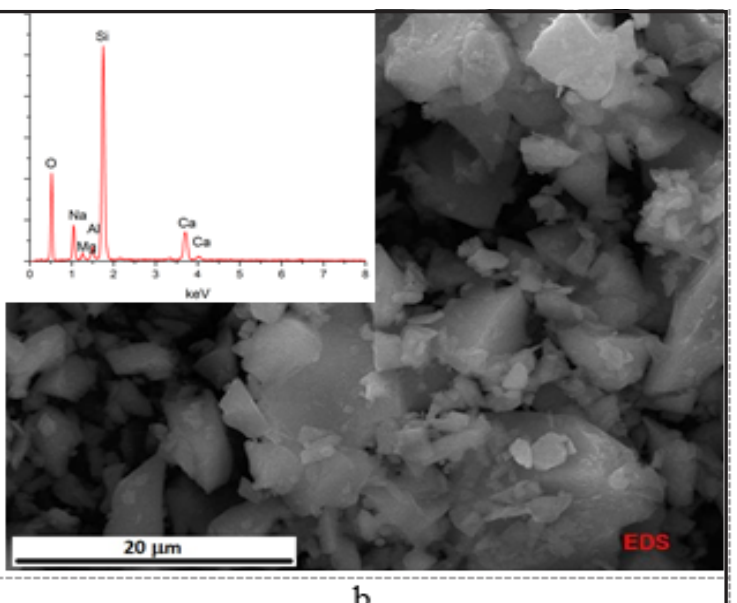

$\mathrm{b}$

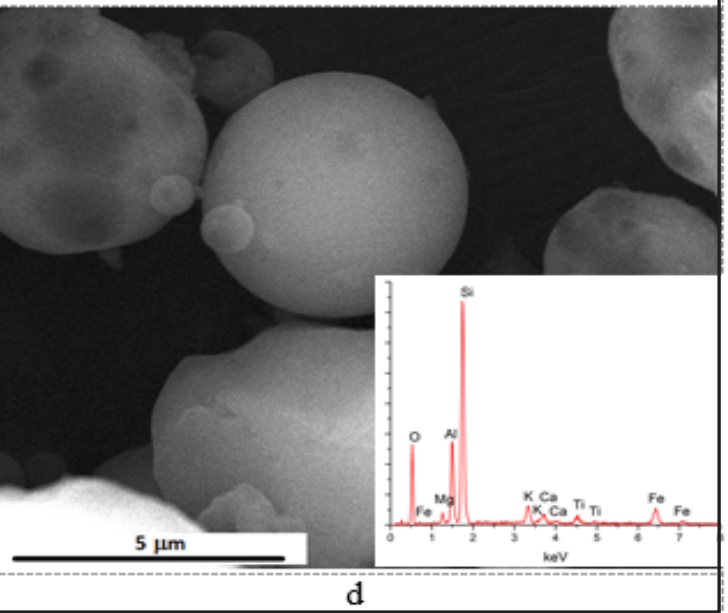

of $\mathrm{Ti}(44 \%)$ and $\mathrm{Al}(13 \%)$; the main compounds assessed by XRD are Ti and titanium oxides [13]. The use of this waste as alternative aggregate in portland cement composites determines the increase of mechanical strengths both at early ( 3 days) and longer hardening times (28 days) [13].

SEM images of this waste (W) are presented in figure 2. As it can be seen, this waste contains big agglomerates of smaller grains as well as hollow of porous microspheres (fig.2c) formed due to the partial melting of titanium alloy [13].

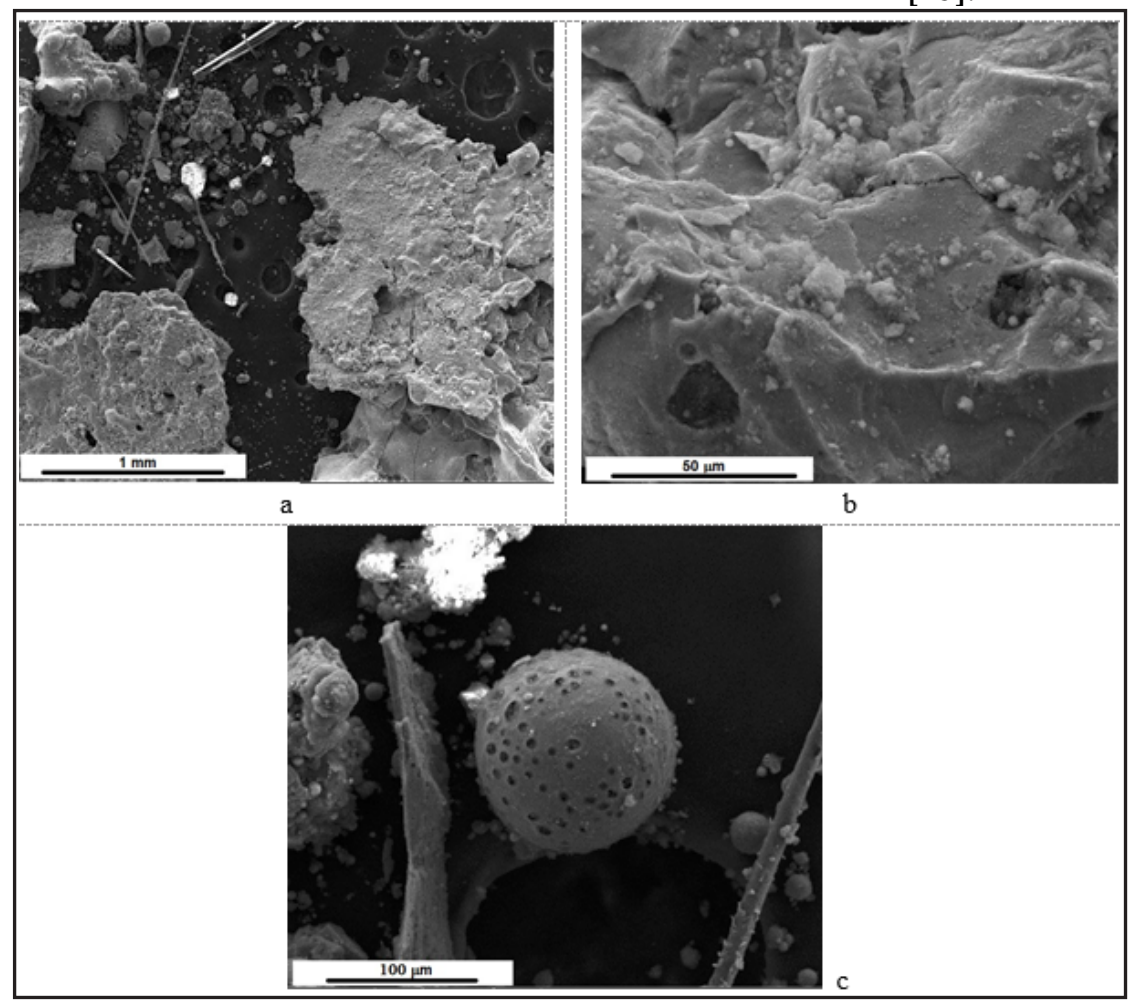

Fig.2. SEM micrographs of titanium waste (W) 
Table 1

THE COMPOSITION OF AABSIPS WITH FLY-ASH (PASTE AND MORTAR)

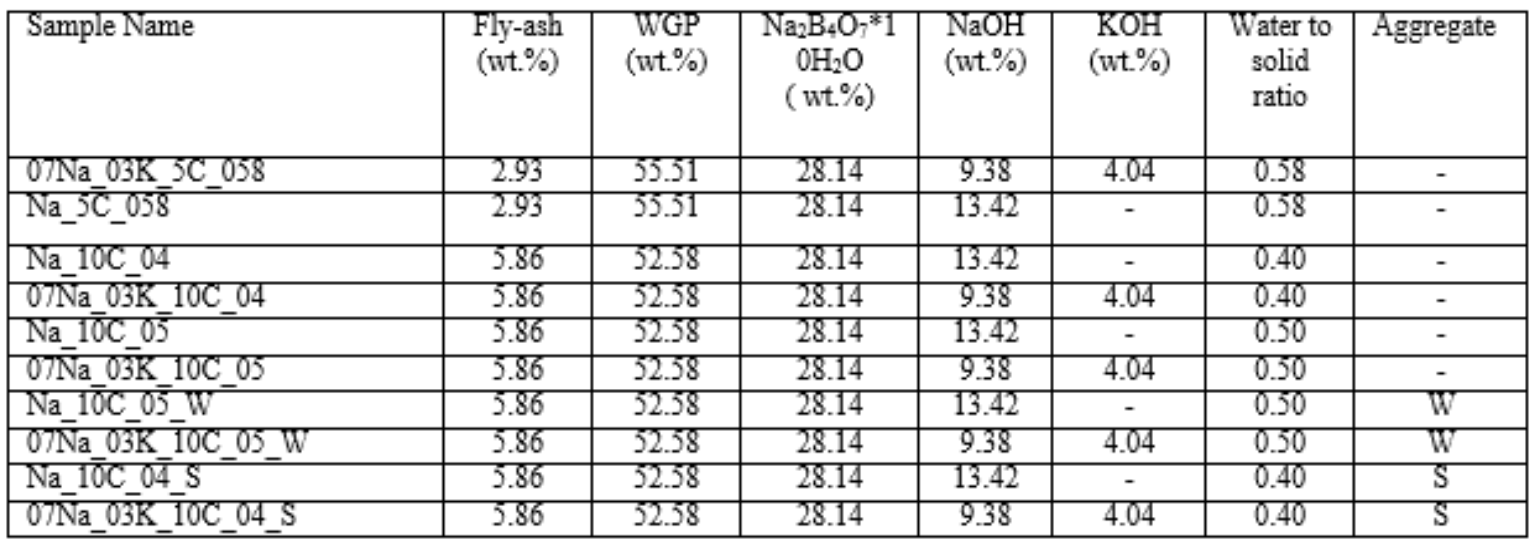

Both aggregates ( $\mathrm{S}$ and $\mathrm{W}$ ) had the following particle size distribution: $11 \%$ - below $0.15 \mathrm{~mm} ; 22 \%$ between 0.15 $0.5 \mathrm{~mm} ; 33.5 \%$ between $0.5-1 \mathrm{~mm}$ and $33.5 \%$ between 1 $2 \mathrm{~mm}$.

\section{AABSIPs preparation}

The composition of AABSIPs, pastes and mortars, are presented in Table 1. In mortar compositions the aggregate to binder ratio was 1:1.

The AABSIPs compositions were labeled considering the following: composition of alkali activator solution ( $\mathrm{Na}$ $100 \% \mathrm{NaOH}$ or $07 \mathrm{Na} 03 \mathrm{~K}-70 \% \mathrm{NaOH}+30 \% \mathrm{KOH}$ ), the amount of fly ash substituting waste glass powder (5C-5 wt.\% or 10C-10 wt.\%), liquid to solid ratio (058-0.58; 050.50; 04-0.40), type of aggregate (S or W) for mortars.

AABSIPs were obtained by the dry mixing of solid components i.e. glass powder, fly ash (and aggregate in the case of mortars) with the alkaline activator solution; this solution was obtained by the alkaline hydroxides and borax decahydrate solubilization in water. The mixture was homogenized for $5 \mathrm{~min}$ with a mechanical stirrer $(800 \mathrm{rpm})$. The pastes were cast in cylindrical molds $(\phi=34 \mathrm{~mm}$ and $\mathrm{h}=15 \mathrm{~mm}$ ) and the mortars were cast in rectangular prism

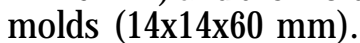

To increase the rate of hardening process, the samples were cured at $60^{\circ} \mathrm{C}$ the first a $24 \mathrm{~h}$, and afterwards in air at $20+2^{\circ} \mathrm{C}$.

The microstructure of AABSIP mortars, before and after thermal treatment, was assessed by Scanning Electron Microscopy (SEM). SEM/BSE images and the EDAX spectra were obtained using a high-resolution electronic scanning microscope (FEl Inspect F50) with a resolution of $1.2 \mathrm{~nm}$ at $30 \mathrm{kV}$ and $3 \mathrm{~nm}$ at $1 \mathrm{kV}$ (BSE) and EDAX accessory.

The X-Ray diffraction analysis of fly ash were performed at room temperature using a PANalytical Empyrean diffractometer with $\mathrm{Cu} K \alpha(\lambda=0.154 \mathrm{~nm})$ radiation, and the scanning was performed between $2 \theta=5$ and 65 degree.

All pastes and mortars were thermally treated in air for one hour in an oven (heating rate $=10^{\circ} \mathrm{C} / \mathrm{min}$ ) at the following temperatures: $250,400,600,650$ and $700^{\circ} \mathrm{C}$.

Volume and mass variations after thermal treatment were calculated using formulas (1) and (2) respectively [11,12]:

$$
\Delta V=\left[\frac{V f-V i}{V i}\right] \times 100(\%)
$$

where:

$\mathrm{Vi}=$ sample volume before heat treatment;

$\mathrm{Vf}=$ sample volume after heat treatment.

$$
\mathbf{\Delta} m=\left[\frac{m f-m i}{m i}\right] \times 100(\%)
$$

where:

$\mathrm{mi}=$ sample mass before thermal treatment;

$\mathrm{mf}=$ sample mass after thermal treatment.

\section{Results and discussions}

The visual aspect of AABSIP pastes with various amounts of fly ash additions, before and after thermal treatment at different temperatures is presented in table 2 .

For all AABSIP pastes, the intumescent process (specimens' swelling) can be visually noticed starting from $600^{\circ} \mathrm{C}$ (table 2 and fig. 3a). The substitution of $\mathrm{NaOH}$ with $30 \% \mathrm{KOH}$ has no noticeable influence on the volume change (DV) for the AABSIP pastes thermally treated at $600^{\circ} \mathrm{C}$ and $650^{\circ} \mathrm{C}$. The further increase of temperature causes a decrease of $\Delta V$ due to a creep phenomenon that causes the material to rearrange under its own weight as the material's temperature approaches to the value of softening/flow temperature characteristic for alkali silicate hydrates.

The intumescent process is determined by the loss of water bound in sodium/potassium silicate/aluminate hydrates, compounds formed by the alkaline activation of WGP/fly ash; the water loss from sodium borate hydrate, resulted in the borax reaction with $\mathrm{NaOH}$ solution, contributes also to the intumescent process [11,12]. A confirmation of this process is provided by the important mass losses (ranging from 22\% to 26\%) recorded for thermally treated pastes (fig. 3b)

For the AABSIPs with a higher amount of fly ash (10 wt.\%), a small swelling is noticed even at $400^{\circ} \mathrm{C}$ (fig. 4a). The mass losses for these compositions are comprised between 30 and $38 \%$ (fig.4b) and are higher in comparison with those recorded for the AABSIPs with 5 wt. $\%$ fly ash (fig.3b). A possible explanation for these higher mass losses ( $\mathrm{Dm})$ can be due to the formation of a higher amount of sodium/potassium silicate/aluminate hydrates or/and geopolymeric gel by the alkaline activation of fly ash (present in this system in a higher amount).

The visual aspect of AABSIP mortars, before and after thermal treatments, is presented in table 3 .

As it can be seen from table 3 and figure 5, the largest volume increases are recorded at $650^{\circ} \mathrm{C}$. One can notice also the lower values of volume increase $(\Delta \mathrm{V})$ recorded for the AABSIPs mortars as compared with those recorded for the corresponding AABSIP pastes (fig.4a). These data confirm the important role exerted by the AABSIP matrix on the intumescent process; nevertheless, when the sand was replaced with titanium waste, a significant decrease of swelling (intumescent) phenomenon was observed; this can be correlated with the higher thermal stability of titanium waste at higher temperatures as compared with silica sand [14]. 
Table 2

AABSIP PASTES, WITH 5 wt. \% AND 10 wt. \% FLY ASH ADDITIONS, BEFORE AND AFTER THERMAL TREATMENT AT DIFFERENT TEMPERATURES
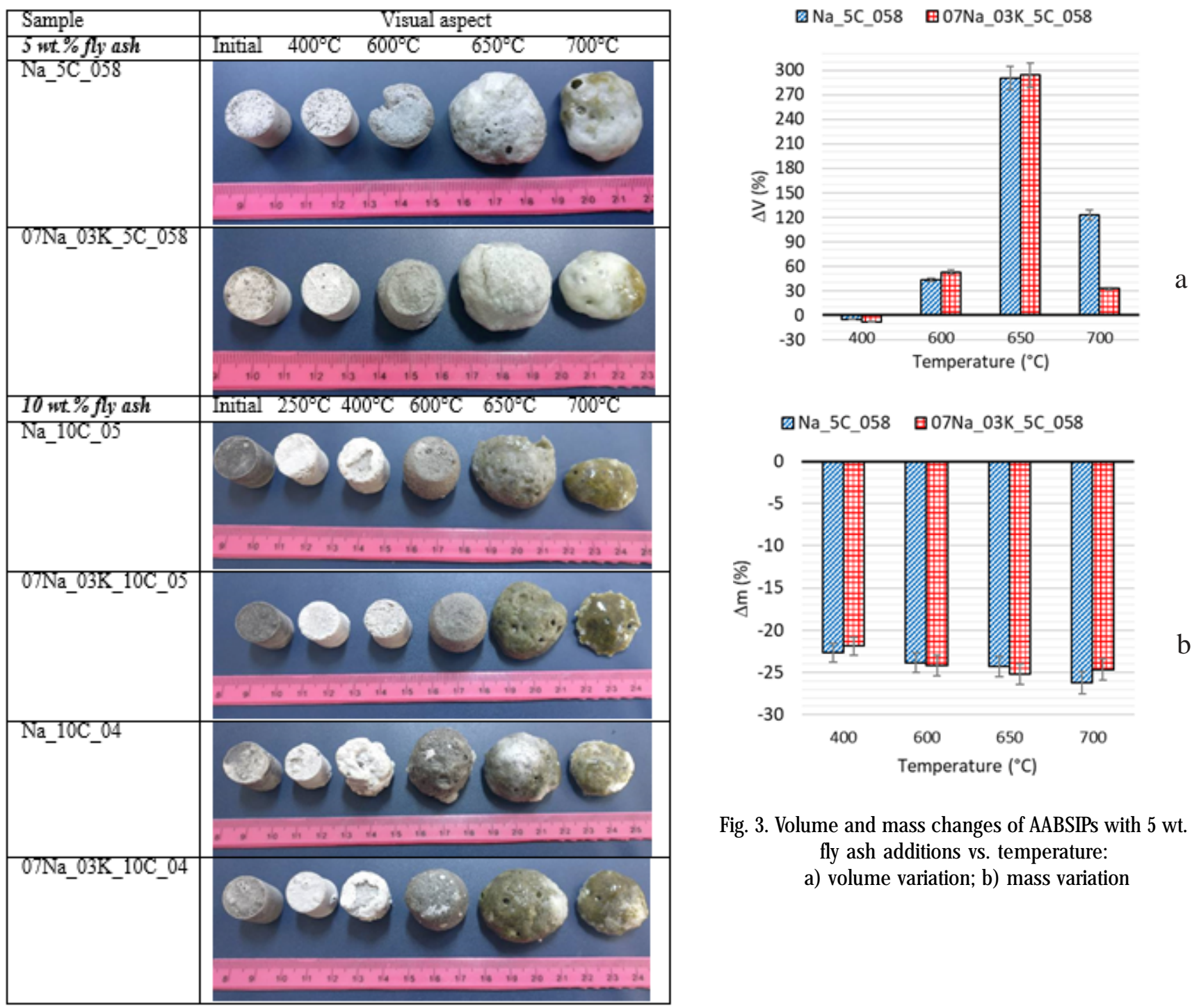

๒ $\mathrm{Na}$ 5C_058 日07Na_03K_5C_058

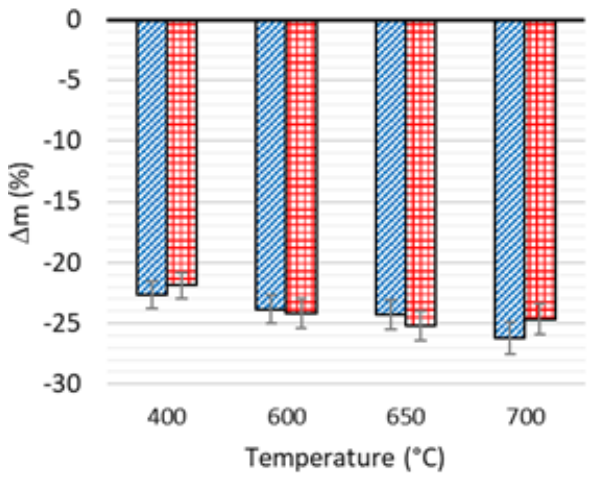

Fig. 3. Volume and mass changes of AABSIPs with 5 wt. \% fly ash additions vs. temperature:

a) volume variation; b) mass variation

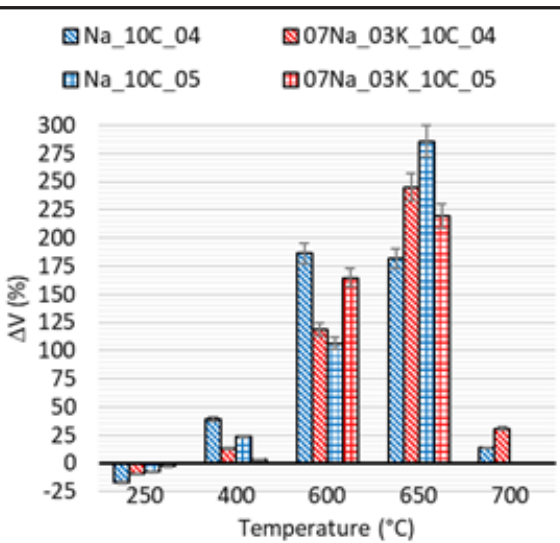

The increase of temperature causes also a weight loss for all AABSIP mortars, ranging from 12 to $14 \%$ for the sample with sand as aggregate and between 7 and $10 \%$ for the samples with titanium waste as aggregate (fig.6). This mass loss is mainly due to the decomposition of hydrates from the AABSIP paste.

Moreover, due to its complex composition [13] titanium waste (W) exhibits mass modification during the thermal treatment (fig. 7).

For the thermal treatment at $400^{\circ} \mathrm{C}$ and $600^{\circ} \mathrm{C}$, titanium waste exhibits mass loss probably due to the burning of impurities present in this waste; at $700^{\circ} \mathrm{C}$ is noticed a mass increase (around $2 \%$ ) and can be attributed to various chemical processes including titanium oxidation. According to Kellerer and Winge [15] titanium oxidation determines also a volume increase.

The compressive strengths of AABSIP mortars (fig.8) are in good correlation with their microstructure (figs. 911).

The compressive strengths (fig. 8), show a different variation vs. temperature in correlation with the aggregate type. For the mortar prepared with sand as aggregate (fig.8a) the compressive strengths decrease with the 

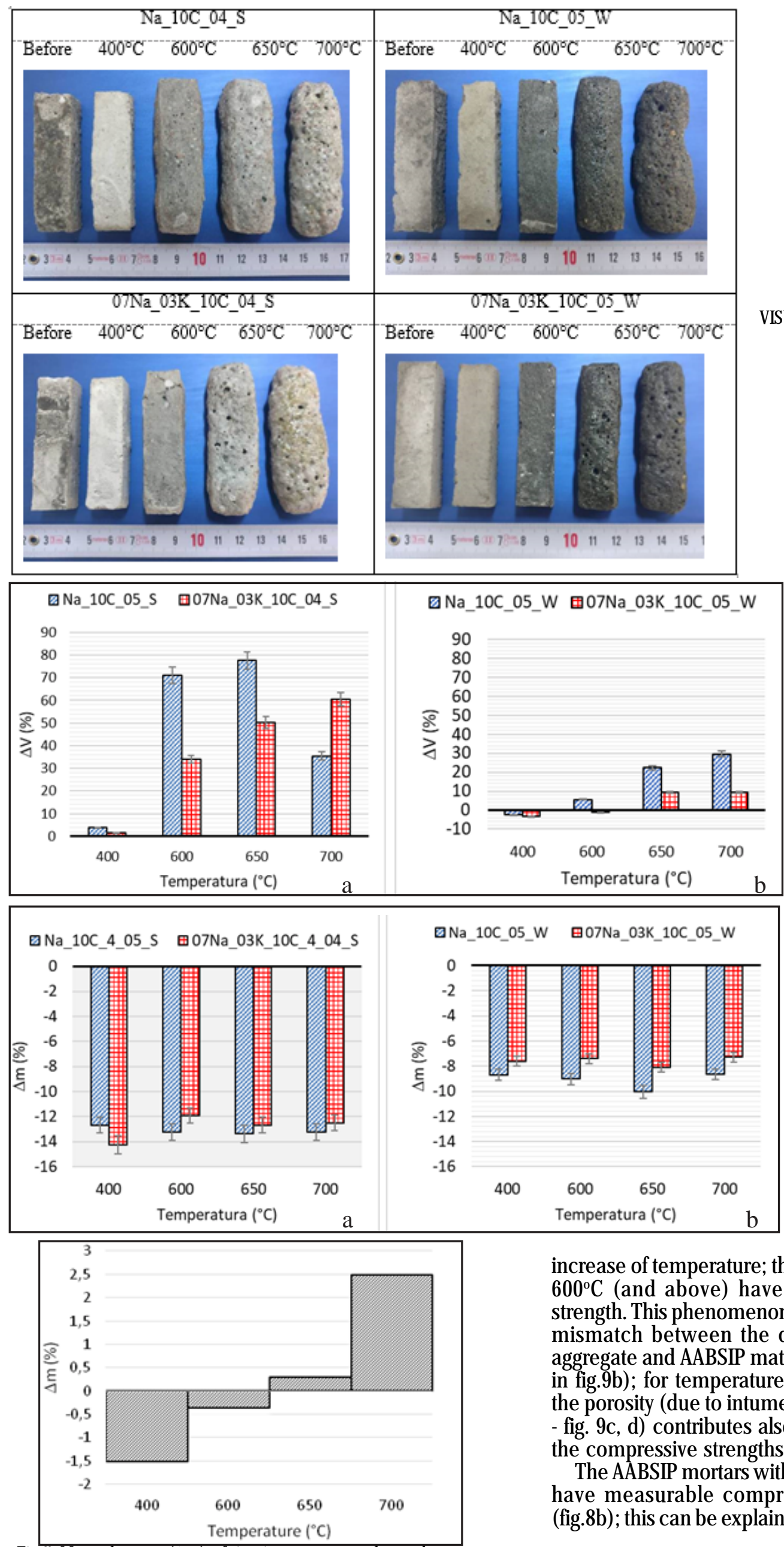

Fig.7. Mass changes $(\Delta \mathrm{m})$ of titanium waste $v$ s. thermal treatment temperature

REV.CHIM.(Bucharest) $\bullet 70 \bullet$ No. $2 \bullet 2019$
Fig. 5. Volume changes of AABSIP mortars with fly ash additions vs. temperature:

a) aggregate - silica sand;

b) aggregate - titanium waste

Fig.6. The mass change of AABSIP mortars with fly ash additions vs. on temperature:

a) aggregate - sand; b) aggregate titanium waste

increase of temperature; the specimens thermally treated $600^{\circ} \mathrm{C}$ (and above) have no recordable compressive strength. This phenomenon can be explained by a thermal mismatch between the dilatation coefficient of silica aggregate and AABSIP matrix (see arrows pointing cracks in fig.9b); for temperatures above $600^{\circ} \mathrm{C}$ the increase of the porosity (due to intumescent process of AABSIP paste - fig. $9 c, d)$ contributes also to the important decrease of the compressive strengths.

The AABSIP mortars with titanium waste (as aggregate) have measurable compressive strengths up to $700^{\circ} \mathrm{C}$ (fig.8b); this can be explained by a very good compatibility 


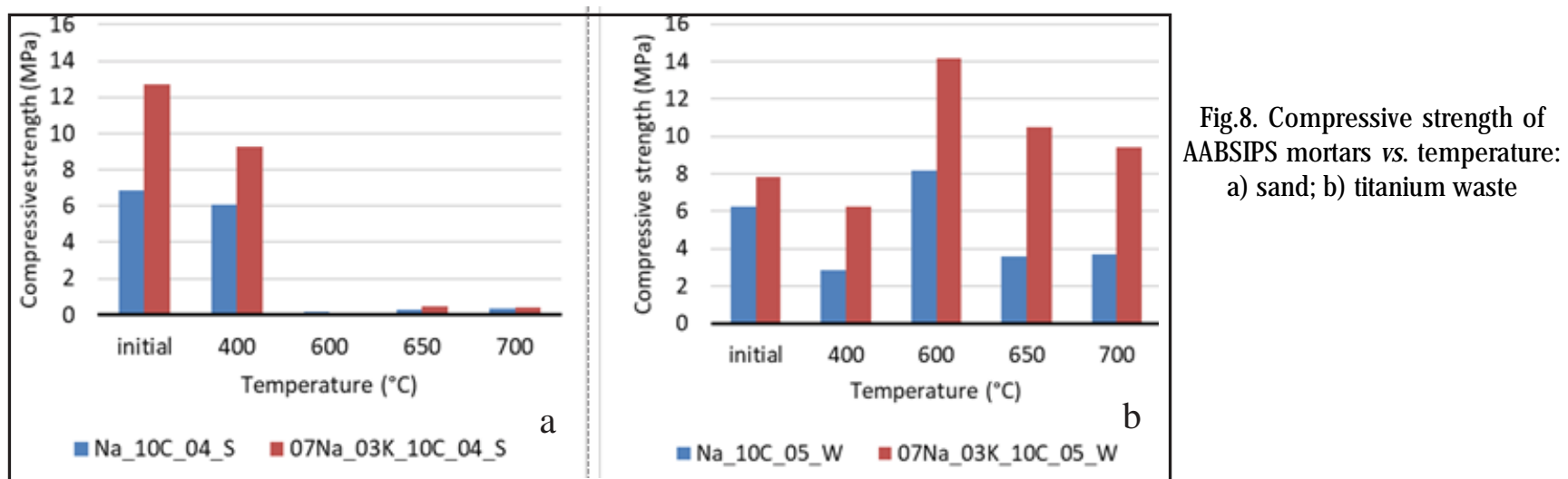

between the aggregate grains (lighter in BSE images from fig. 10) and the surrounding AABSIP matrix (darker).

The increase of the compressive strengths of AABSIP mortars with titanium waste (as aggregate) when the temperature increases from 400 to $600^{\circ} \mathrm{C}$, could be due to a sintering process. The partial softening (increase of flowability) of the matrix (fig. 11d) could determine also a certain reduction of the porosity especially in the interfacial transition zone between the AABSIP matrix and aggregate (see arrow fig. 11c). The further decrease of compressive
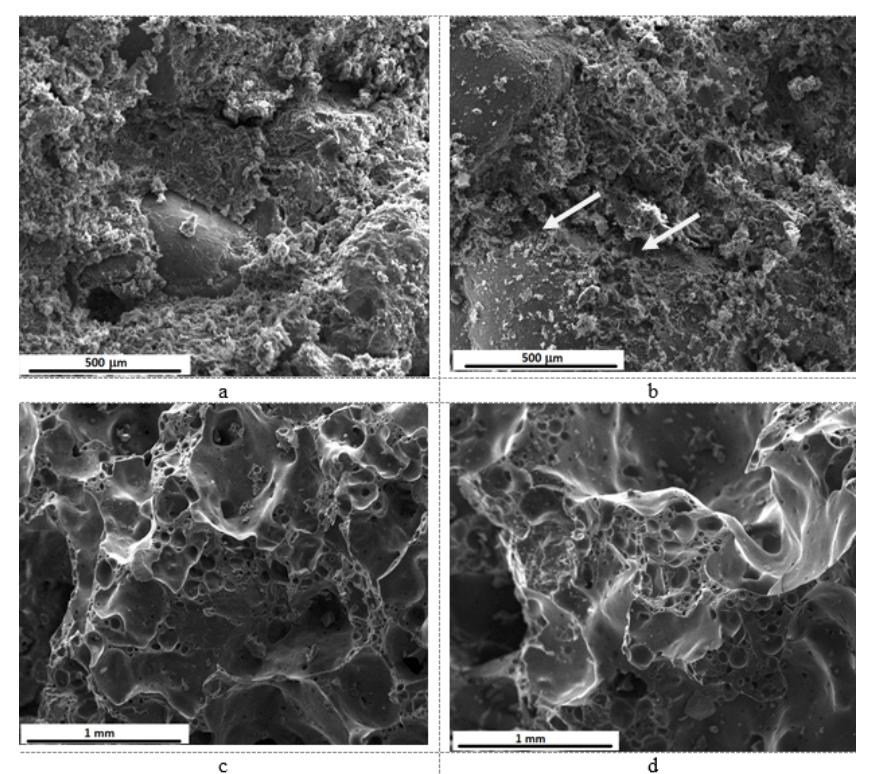

Fig.9. SEM images of the 07N_03K_10C_S (AABSIP mortar with sand aggregate) before thermal treatment $(\mathrm{a}) \overline{\text { and }}$ after thermal treatment at: b) $400^{\circ} \mathrm{C}$; C) $600^{\circ} \mathrm{C}$; d) $650^{\circ} \mathrm{C}$.

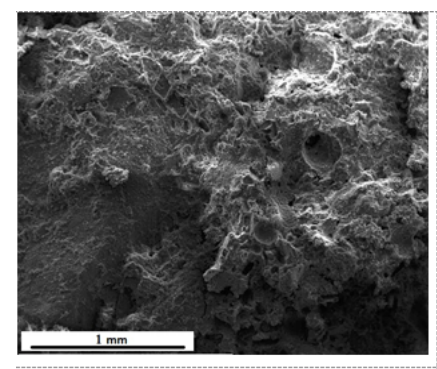

a

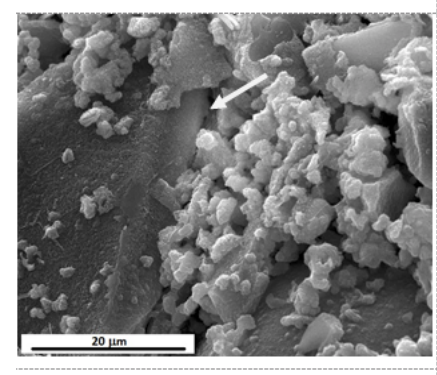

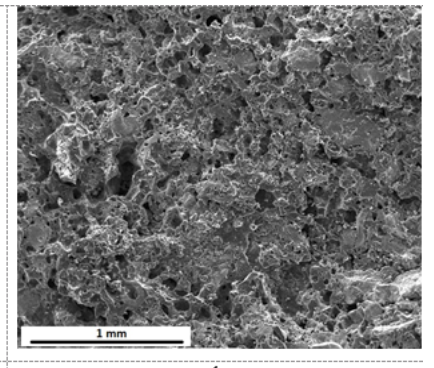

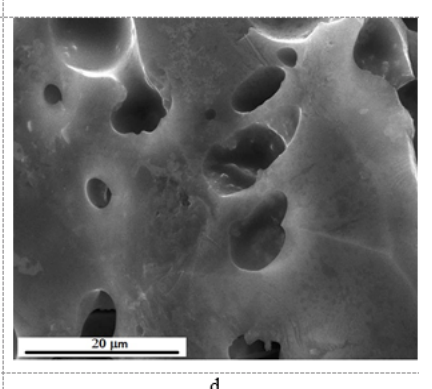

strengths of these mortars with the increase of temperature up to $700^{\circ} \mathrm{C}$ could be due both to the intumescent process of AABSIP paste as well as volume increase of $W$ aggregate due to its oxidation [15].

One can also notice from figure 8 the higher mechanical strength of AABSIP mortars activated with a mixture of $70 \% \mathrm{NaOH}$ and $30 \% \mathrm{KOH}$, in comparison with those activated with $\mathrm{NaOH}$ solution. This may be due to the extent of alkaline activation process of WGP and fly ash correlated with the stabilization of large silicate oligomers in the presence of potassium ions [16].
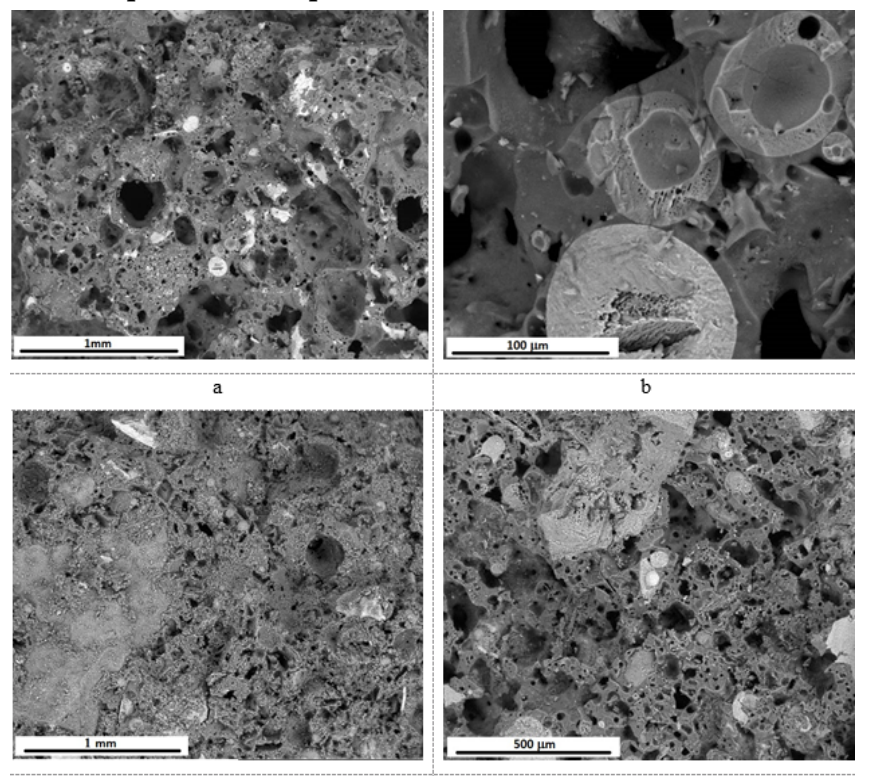

d

Fig.10. BSE images of Na_10C_05_W mortar after thermal treatment

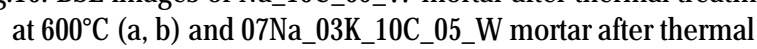
treatment at $400^{\circ} \mathrm{C}(\mathrm{C})$ and $600^{\circ} \mathrm{C}(\mathrm{d})$

Fig.11. SEM images of 07Na_03K_10C_05_W mortar after thermal treatment at $400^{\circ} \mathrm{C}(\bar{a}, \mathrm{c}) \overline{\text { and }} \overline{600}{ }^{\circ} \mathrm{C}(\mathrm{b}, \mathrm{d})$ 


\section{Conclusions}

Intumescent materials AABSIP (pastes and mortars) were obtained by the alkali activation of a mixture of waste glass pow der and fly ash. The alkali activators used in this study were mixtures of borax decahydrate with $\mathrm{NaOH}$ solution or a mixture of $\mathrm{NaOH}$ and $\mathrm{KOH}$ solutions. The intumescent process (important swelling) occurs during the thermal treatment of AABSIP pastes at temperatures ranging between $600-700^{\circ} \mathrm{C}$.

For the preparation of AABSIP mortars two types of aggregates were used i.e. sand and a waste resulted during the mechanical processing of titanium alloy ingots. The partial replacement of $\mathrm{NaOH}$ with $\mathrm{KOH}(30 \%)$ causes an increase in the mechanical strength of AABSIP mortars, irrespective of the aggregate type.

The volume increase (swelling) of AABSIPS mortars is smaller in comparison with the one assessed for the corresponding AABSIP pastes; these data confirm the important role exerted by the AABSIP matrix on the intumescent process as well as the nature of aggregate (sand or titanium waste).

The SEM images of AABSIP mortars show the formation of a binding matrix by the alkaline activation of the WGP and fly ash, which adheres very well to the aggregate grains. The thermal treatment leads to the formation of round pores in the binding matrix which join together to form large pores of different shapes and sizes.

Based on the AABSIPs properties assessed in this study, a potential utilization of these materials can be as lowcost fire-stopper blocks (bricks) for passive fire protection in civil and industrial buildings.

Acknowledgements: The XRD analyzes were possible due to Sectoral Operational Programme Human Resources Development, financed from the European Social Fund and by the Romanian Government under the contract number POSDRU/86/1.2/S/58146 (MASTERMAT), and the SEM analyzes were possible due to EU-funding project POSCCEA2-02.2.1-2013-1/Prioritary Axe 2, Project No. 638/12.03.2014, ID 1970, SMIS-CSNR code 48652

\section{References}

1.DAVIDOVITS, J., SAWYER, JL., United States Pat., 4, 1985, p. 1-12. 2.DAVIDOVITS, J., J. Therm. Anal., 37, 1991, p. 1633-56.

3.LYON, R. E., BALAGURU, P.N., FODEN, A., SORATHIA, U., Fire Mater., 21, 1997, p. 67-73.

4DAVIDOVITS, J., Geopolymer Chemistry and Applications. 2008.

5.DUXSON, P., FERNANDEZ GIMENEZ, A., PROVIS, J., LUKEY, G., PALOMO, A., VAN DEVENTNER, J.S.J ., J. Mater, Sci., 42, 2007, p. 29172933.

6.PAPAKONSTANTINOU, C.G., Compos. Part. B Eng., 32, 2001, p. 63749.

7.WILLIAMS, R.P., VAN RIESSEN, A., J. Eur. Ceram. Soc., 31, 2011, p. 1513-6.

8.NAZARI, A., MAGHSOUDPOUR, A., SANJAYAN J.G., Constr. Build. Mater., 70, 2014, p. 262-8.

9.BADANOIU, A.I., AL SAADI, T.H.A., STOLERIU, S., VOICU, G., Constr. Build. Mater., 84, 2015, p. 284-293.

10.BADANOIU, A.I., AL SAADI, T.H.A., VOICU, G., Int. J . Miner. Process., 135, 2015, p. 1-10.

11.AL SAADI, T.H.A., BADANOIU, A.I., NICOARA, A.I., STOLERIU, S., VOICU, G., Constr. Build. Mater., 136, 2017, p. 298-306.

12 NICOARA, A.I., BADANOIU, A., VOICU G., Rev. Romana. Mater. / Rom. J. Mater., 49, 2019, p.23-32

13.BARBULESCU, L., BADANOIU, A., NICOARA, A., PIRVU, C., Rev. Romana. Mater. / Rom. J. Mater., 46, 2016, p. 369-75.

14.KOWALSKI, J.S., Arch. Foundry Eng., 3, 10, 2010, p. 111-114.

15.KELLERER, H.W.L., Metall. Trans., 2, 2017, p. 113-115.

16.KRIVEN, W.M., BELL, J.L., 28th Int. Conf. Adv. Ceram. Compos. B Ceram. Eng. Sci. Proc., 2004, p. 99-104.

Manuscript received: 23.10 .2018 